\title{
Preventing predatory publications: Role of librarian and government agencies
}

\author{
Dipali S Mahajan ${ }^{*}$, Nitin A Mali \\ ${ }^{\mathbf{1}}$ Assistant Librarian, ${ }^{2}$ Librarian, ${ }^{1}$ Dept. of Library, SPTM NMIMS Shirpur, Dhule, Maharashtra, ${ }^{2} \mathrm{R}$ C Patel Institute of Pharmaceutical
} Education and Research Shirpur, Dhule, Maharashtra, India

*Corresponding Author: Dipali S Mahajan

Email: dsmahajan20@gmail.com

\begin{abstract}
Predatory publication is the latest threats emerged to the integrity of academic publishing. These publications in open access and paid journals have paved the way for low-quality articles. These publications lack the authentication of appropriateness of publications such as peer review, editing, editorial boards, editorial offices, and other editorial standards, imposing a number of new ethical issues in publishing research papers. Research publications carry significant importance in Indian universities when considering faculty selection, promotions, and increment. It is utmost responsibility of authors to promote publication ethics. Currently the government is cracking down on predatory publication practice. Academic agency like UGC and the All India Council for Technical Education (AICTE) made fully responsible for ensuring quality control and monitoring of academic journals. Librarians have a key role to play in educating users about predatory publishing. Collaborative efforts of authors, library professional and government agencies may prevent predatory publications.
\end{abstract}

Keywords: Predatory Publication, Government regulation, Librarian, Open access publication.

\section{Introduction}

Predatory journals are journals that charge an article processing charges to authors; however, they lack the authentication of legitimate scholarly journals such as peer review, editing, editorial boards, editorial offices, and other editorial standards, imposing a number of new ethical issues in publishing research papers. Numerous ethical issues such as lack of editorial and publishing standards, misuse of research funding, no reliable research literature, and misrepresentation are linked with these journals. ${ }^{1}$ Article publishing fees are not disclosed to the author at the time of submission of manuscript by many of these journals, but eventually, authors are made to pay bills, "without robust editorial or publishing services." 2 The predatory journals send almost daily send email to many academics, inviting them to submit articles in the journals and offering a short turnaround time from submission to publication. Unfortunately, the differentiation between predatory and authorized journals is often difficult, posing risk of authenticated studies being published in such journals. These journals are seriously affecting reliability of science by decline peer review, are contaminating the scientific literature, and are polluting ethics in scientific publishing. ${ }^{2}$

Beall, a librarian of the University of Colorado, first person coined illegal publishers and journals as "predatory." $\mathrm{He}$ blacklisted these journals on his notorious blog called Scholarly Open Access. ${ }^{3}$

In 2010, the University Grants Commission, India's higher education regulator, introduced the Academic Performance Indicators in which it made research compulsory for teachers across all kinds of higher education institutions, including teaching-focused colleges, for career advancement. The insistence on research from all teachers without consideration of, among others, infrastructural deficits (poor libraries and other research facilities) at the majority of institutions and poor knowledge and skills for research among most teachers, was foolish. With research and publishing made compulsory, a large number of teachers took the easiest option, of publishing in fake journals. ${ }^{4}$

A UGC decision in 2010 making research compulsory for teachers to rise up the ladder prompted some to pay suspicious publications to feature their work. Research publications carry significant importance in Indian universities when considering faculty selection, promotions, and increment. Numerous Indian institutes and universities have made it mandatory to have certain number of publications before submitting Ph.D. thesis and also to be a recognized $\mathrm{Ph}$. D guide. These provisions compel researchers to publish within stipulated time posing risk to ethical publishing. Furthermore, young researchers lack clarity about the content to be considered as a "research publication" which enhances the desperation to publish by any means.

\section{India's leading role}

Among the key findings of Demir's study is that $62 \%$ of stand-alone fake journals are published in India and Indian researchers contributed 2,592 articles of a total of 24,840 $(10.4 \%)$. On the face of it, this seems to make Indian contributions less impressive except for the fact that the numbers are very high relative to the total research output of Indian researchers.

\section{Why to Prevent?}

Predatory journals possess biggest threat to research ethics as they lack peer review: a hallmark of scholarly publication. Furthermore, content published in these journals may be plagiarized, could be potentially fraudulent, and is impossible to be published in authenticated journals. Some authors may accidentally publish their legitimate research in these journals due to lack of ability to identify them as unauthenticated journals. It also makes difficult for research enterprise to decide whether to rely on the results of studies published in these journals or not, while reviewing literature 
for further studies. ${ }^{5}$ The various ethical issues related to these journals include:

1. Misrepresentation: Predatory journals distort who they are and what services they offer.

2. Lack of editorial and publishing standards and practices: These journals lack standards and best practices as established by the scholarly publishing community.

3. Academic deception: Authors if publishing in predatory journals may try to present them as genuine peer-reviewed journals while listing those publications on their curriculum vitae. Citing the articles as genuine publications causes misrepresentation of authors' scholarly effort and academic deception.

4. Research and funding wasted: Research published in predatory journals may not receive the recognition it deserves and may become inaccessible, hence the effort and risk of research as well as funding are wasted.

5. Lack of archived content: Predatory journals generally avoid archiving their content in third-party sites such as PubMed Central, Google scholar etc.

6. Undermining confidence in research literature: Most of the readers fail to distinguish between predatory and legitimate journals, thus question the scientific process, and undermine the work of all researchers

\section{Role of Librarian}

Librarians have a key role to play in educating users about predatory publishing. Predatory publishing can be described as low quality, amateurish, and often unethical academic publishing that is usually Open Access (OA). Understanding predatory publishing helps authors to make more informed decisions about where to publish. In the process of educating our users, librarians can set the ground for important conversations that encourage critical thinking about the scholarly communications process. Predatory publishing starts from broader problems including over emphasis on publication quantity, an OA models based on traditional, forprofit publishing, and resource disparities. A more sustainable and just scholarly communications ecosystem can be a reality. As effective supporters for predatory publishing, librarians need to be ready to respond to those who involved in predatory publishing. It is helpful to contextualize predatory publishing as an aspect of evaluating publishers and the quality of scholarship. This helps promote the idea that due carefulness is the responsibility of all scholars, whether as authors, peers, or administrators. ${ }^{6}$

\section{Role of government regulatory agencies}

Savitribai Phule Pune University, India, was one of the first to issue warning to authors against publishing in unreliable journals and formulated "Guidelines for Research Publications." Few of the Indian universities have well adopted these guidelines; however, overall situation in India has only deteriorated over the last decade.

To reduce the practice of publishing in sub-standard journals, the UGC released a white list of approved journals in January 2017. The list contained approximately 32,000 publications indexed on science-citation databases such as Web of Science and Scopus, as well as more than 5,000 publications recommended by universities. But researchers quickly pointed out that it also included predatory journals.

The UGC removed more than 4000 journals from the list on the basis of poor quality, or because incorrect or insufficient information about the journal had been provided.

Bhushan Patwardhan, presently vice chairman UGC, said the Indian government agencies should show zero tolerance towards academics who publish in predatory journals. There are currently no consequences for those who do this. He stated need to introduce similar regulations introduced to detect and punish plagiarism at universities. The government could help stop proliferation of these fake journals by deep-cleaning and rigorously maintaining this UGC list. It should also introduce ethical publishing training as part of doctoral research. Furthermore, the government could introduce tangible and measurable alternatives to publishing, such as 'social impact of research', as a yardstick to measure success.

\section{Conclusion}

Predatory journals are one of the latest threats emerged to the integrity of academic publishing. These journals have paved the way for low-quality articles by exploiting open-access publishing, threatening standards of evidence-based science. It is the utmost need of authors to selectively target journals and publish in compliance with the established norms of publishing ethics. Predatory publishing is an exciting opportunity for librarians to educate their colleagues, teaching faculty, administrators, students, and others to move them away from dependence on OAP. Regulatory bodies like the UGC and the All India Council for Technical Education (AICTE) should be fully responsible for ensuring quality control and monitoring of academic journals. Government funding agencies and academics need to develop mutual trust and work together to solve this problem. Both must realise that there is no easy, quick fix, such as publishing an ad-hoc list of predatory journals or declaring that all paid journals are predatory.

\section{Conflict of Interest}

The authors declare that there are no conflicts of interest in this paper.

\section{Source of Funding \\ None.}

\section{References}

1. Ferris LE, Winker MA. Ethical issues in publishing in predatory journals. Biochem Med (Zagreb). 2017;27:279-84.

2. Gerberi DJ. Predatory journals: Alerting nurses to potentially unreliable content. Am J Nurs. 2018;118:62-5.

3. Beall J. Predatory journals: Ban predators from the scientific record. Nature 2016;534:326.

4. Seethapathy GS, Santhosh Kumar JU, Hareesha AS. India's scientific publication in predatory journals: Need for regulating 
quality of Indian science and education. Curr Sci. 2016;111:1759-64.

5. Choudhary M, Kurien Predatory journals: A threat to evidencebased science. Indian J Health Sci Biomed Res. 2019;12:12-4.

6. Monica Berger, Everything You Ever Wanted to Know About Predatory Publishing but Were Afraid to Ask. Baltimore, Maryland. 2017:22-5.
How to cite: Mahajan DS, Mali NA. Preventing Predatory Publications: Role of Librarian and government agencies. IP Indian J Libr Sci Inf Technol. 2021;6(1):1-3. 